\title{
A Study on the Correlations of Self-Esteem, Self-Efficacy, and Learning Motivations of Underachieving Elementary School Students
}

\author{
Hi-Yoean Han1), Soon-Gil Park²)
}

\begin{abstract}
This study aims to identify the differences in self-esteem, self-efficacy, and learning motivations of underachievement children and to identify the variables that affect learning motivations. The participants of this study were 90 underachievement children and 90 general children in fourth, fifth, and sixth grades of elementary school from three elementary schools of G Metropolitan City. The underachievement children are those who showed underachievement in Korean, English, and Mathematics. The tools used in this study are 40 items from the self-esteem scale, 25 items from the self-efficacy scale, and 25 items from the learning motivation scale. The statistical processes used in this study are descriptive statistics, reliability analysis, t-tests, correlation analysis, and regression analysis. The results are as follows. First, underachievement children showed lower performances in self-esteem, self-efficacy, and learning motivations than general children. Second, the learning motivations of underachievement children were highly correlated with self-esteem and self-efficacy. Third, the predictor of learning motivations from both underachievement children and general children was preferences in task difficulties. Therefore, with bad academic performance, negative self-esteem in particular, was formed in the group of underachieving children. The underachieving children make less effort to complete given tasks. In conclusion, it seems necessary to figure out a proper way to improve the confidence of underachieving children in general academic circumstances, such as through developing their self-esteem, encouraging their expectations on successfully finishing tasks, and supporting them to study according to their own internal motives. Moreover, it is necessary to provide various educational programs appropriately.
\end{abstract}

Keywords: Underachievement, Learning Motivations, Self-esteem, Self-efficacy

\section{Introduction}

Underachievement refers to difficulties a lack of learning skills, or failure to meet the minimum academic level[1]. In addition, underachievement children are defined as children who do not

Received(April 9, 2020), Review Result(1st: May 29, 2020, 2nd: July 10, 2020), Accepted(July 27, 2020)

1) (Student) 62271 Degree of Master of Education, Nambu Univ., 23 Chumdan Jungang-ro, Gwangsan-gu, Gwangju, South Korea email: hihan25@naver.com

2) (Professor, Corresponding Author) 62271 Dept. of Elementary Special Education, Nambu Univ., 23 Chumdan Jungang-ro, Gwangsan-gu, Gwangju, South Korea

email: psoongil@nambu.ac.kr 
A Study on the Correlations of Self-Esteem Self-Efficacy, and Learning Motivations of Underachieving Elementary School Students

show an expected level of academic achievement from a certain age, resulting in falling short from their school grades or show poor learning speed[2]. Underachievement can lead to including attention deficit, negative sense of self-concept, hyperactivity, impulsiveness, aggression, low learning motivations[3].

Korean government started to develop data for underachievement children at a national level from the early 1980s[4]. In addition, the national assessment that was first conducted in 1998 was expanded and applied to students in the sixth grade of elementary school, third grade of middle school, and first grade of high school from 2008. These results were reflected in the assessment and budget of the Education Offices of each province and city. And all provinces and cities were given learning clinic centers and continuously promoted measures to support basic academic levels[5].

Underachievement children experience lower learning motivations or decrease in self-directed learning skills as they go onto higher grades in school[6]. As underachievement children go through school life, they show a decrease in the levels of learning goals and learning motivations, as well as an increase in negative experiences from learning.

It is reported that underachievement children have low self-esteem due to accumulated failures in learning. The low self-esteem also leads to other academic failures and causes teachers or parents to have low expectations, resulting in self-fulfilling prophecy. To eliminate this vicious cycle, it is necessary for the teachers and parents to systematically plan and provide experiences in success for underachievement children so that they will gain confidence[7]. It is necessary to identify the abilities of each child and encourage children so that they will consider themselves as special people and establish self-esteem. Underachievement children, in particular, have low self-esteem as they negatively assess their value and abilities. As such, it is necessary to actively teach them to understand their own abilities and strengths and think positively about themselves. In order to do so, it is necessary to not only provide the optimal success experiences for underachievement children so that they will experience a sense of interest, challenge and success, but also provide active learning activities so that they will be able to understand and accept themselves, acknowledge others, leading to a positive self-esteem.

In addition, it is necessary to improve the self-efficacy of underachievement children as they go onto higher grades in school. Underachievement children experience a decrease in self-identity due to low leaning achievement motivations in schools, and cause many problematic behaviors such as irrational attitudes towards schools and teachers, poor learning motivations, and inappropriate peer relationships. As a result, this causes social withdrawal, 
making it difficult for them to interact with general children or peers, leading to negative effects on the value, abilities, and expectations for underachievement children in basic learning skills[8] socially.

One of the major causes of underachievement is lack of learning motivations. Underachievement children with a lack of learning motivations fall into regular helplessness, and blame themselves stating that it is no use even if they study. This causes a decrease in self-esteem and leads to overall maladjustment by decreasing confidence in areas other than academics as well.

Students who fall into learned helplessness experience difficulties in starting new things and have difficulties in completing them even if they start something new. It is necessary to correct the negative emotional experiences of underachievement children to provide measures for appropriate academic performances and motivations for life in general. In addition, it is necessary to consider the needs and interests of the students to improve the self-esteem of underachievement children, as well as establish a support system so that the underachievement children can develop their talents and skills.

It is absolutely necessary to accurately diagnose the underachievement factors for students who face difficulties in learning due to multiple reasons, and identify the correlations and effects of self-esteem and self-efficacy on learning motivations to manage school education curriculums. In this sense, this study is absolutely necessary to create an environment where underachievement children with difficult conditions can have dreams and hopes, and make sure they experience a happy school life.

This study identifies the differences in self-esteem, self-efficacy and learning motivations of underachievement children with general children, and aims to define the predictors that affect learning motivations based on the correlations of the variables. The specific research questions are as follows.

First, what are the differences in self-esteem, self-efficacy, and learning motivations between underachievement children and general children?

Second, what are the correlations among self-esteem, self-efficacy, and learning motivations from underachievement children and general children?

Third, what are the variables that affect the learning motivations of underachievement children and general children? 
A Study on the Correlations of Self-Esteem Self-Efficacy, and Learning Motivations of Underachieving Elementary School Students

\section{Study Methods}

\subsection{Study Subjects}

The subjects of this study are 179 students (89 underachievement children and 90 general children) in fourth, fifth, and sixth grades attending D Elementary School, S Elementary School, and O Elementary School in G Metropolitan City. The subjects of this study were children who were judged to be inferior because they did not reach one or more of Korean, mathematics, and English as a result of the assessment of subject learning ability. It is also a child who was selected as a child with poor learning in the evaluation conducted by the school. Those with intellectual disabilities were excluded. General children were students in the $50 \%$ or $60 \%$ percentile of academic achievements.

[Table 1] Characteristics of Research Subjects

\begin{tabular}{|c|c|c|c|c|c|c|c|}
\hline & \multirow[t]{2}{*}{ Classification } & \multicolumn{2}{|c|}{$\begin{array}{c}\text { Underachievement } \\
\text { Children }\end{array}$} & \multicolumn{2}{|c|}{$\begin{array}{l}\text { General } \\
\text { Children }\end{array}$} & \multicolumn{2}{|c|}{ Total } \\
\hline & & $\mathrm{n}$ & $\%$ & $\mathrm{n}$ & $\%$ & $\mathrm{n}$ & $\%$ \\
\hline \multirow{3}{*}{ Grades } & 4 & 30 & 33.7 & 30 & 33.4 & 60 & 33.6 \\
\hline & 5 & 30 & 33.7 & 31 & 34.4 & 61 & 34.0 \\
\hline & 6 & 29 & 32.6 & 29 & 32.2 & 58 & 32.4 \\
\hline \multirow{2}{*}{ Gender } & Male & 51 & 57.3 & 50 & 55.6 & 101 & 56.4 \\
\hline & Female & 38 & 42.7 & 40 & 44.4 & 78 & 43.6 \\
\hline \multirow{4}{*}{ School } & D Elementary School & 45 & 50.6 & 54 & 60.0 & 99 & 55.3 \\
\hline & S Elementary School & 35 & 39.3 & 24 & 26.7 & 59 & 33.0 \\
\hline & O Elementary School & 9 & 10.1 & 12 & 13.3 & 21 & 11.7 \\
\hline & Total & 89 & 100 & 90 & 100 & 179 & 100 \\
\hline
\end{tabular}

\subsection{Study Tools}

\subsubsection{Self-esteem Scale}

This study used the self-assessment scale for children developed by [9] and translated and restructured by [10] to assess self-esteem. The scale has a total of 40 items classified into four sub-variances, with 16 items on general ego that define the general sense of self, 8 items on social ego that looks at oneself within the relationship between friends and peers, 8 items on family ego related to family, and 8 items on academic ego related to adapting to school life.

Answers to each item were based on a five-point Likert scale. The items were scored from 
"Highly Disagree" with one point to "Highly Agree" with five points, and the six negative items $(4,17,23,29,32,38)$ were converted in the opposite. Higher scores in the scale refer to higher self-esteem. The items on self-esteem and Cronbach' a of this study are shown on [Table 2].

[Table 2] Sub-variable and Reliability of the Self-esteem Scale

\begin{tabular}{cccc}
\hline Sub-variables & Number of Items & Items & Cronbach' $^{\prime}$ a \\
\hline General Ego & 16 & $1,2,3,4^{*}, 5,6,7,8,9,10,11,12,13,14,15,16$ & .83 \\
\hline Social Ego & 8 & $17^{*}, 18,19,20,21,22,23^{*}, 24$ & .64 \\
\hline Family Ego & 8 & $25,26,27,28,29^{*}, 30,31,32^{*}$ & .79 \\
\hline Academic Ego & 8 & $33,34,35,36,37,38^{*}, 39,40$ & .75 \\
\hline Total Self-Esteem & & 40 & .91 \\
\hline
\end{tabular}

\subsubsection{Self-Efficacy Scale}

The self-efficacy scale used in this study was the general self-efficacy questionnaire developed by [11] to assess the general self-efficacy of individuals. The scale is consisted of three sub-variables of confidence, self-control efficacy, and preferences in task difficulties, and consists of 25 items in total, with 7, 11, and 7 items in each sub-variable.

The self-efficacy scale is given a score of one to five ranging from "Highly Disagree" to "Highly Agree" depending on how much the participant agrees to a given statement. The scores from the responses are all added up. The items and reliability of the self-efficacy scale are shown in [Table 3].

[Table 3] Sub-variables and Reliability of the Self-efficacy Scale

\begin{tabular}{cccc}
\hline Sub-variables & Number of Items & Items & Cronbach' $a$ \\
\hline Confidence & 7 & $2,6,8,12^{*}, 15,16,19^{*}$ & .67 \\
\hline Self-control Efficacy & 11 & $1^{*}, 3^{*}, 4^{*}, 5^{*}, 7,9,10,14,18,21^{*}, 23$ & .76 \\
\hline Preferences in Task Difficulties & 7 & $11,13,17,20,22,24,25^{*}$ & .78 \\
\hline Total Self-Efficacy & \multicolumn{2}{c}{25} & .83 \\
\hline
\end{tabular}

\subsubsection{Learning Motivation Scale}

This study used the school learning scale of [12] to assess learning motivations. The scale has a total of 25 items, with four sub-variants of non-essential motivations (8 items), essential motivations (7 items), class motivations (4 items), and continuous motivations (6 items). The scores of each item range from 1 to 30, in a rating scale of five stages from "Strongly Disagree" to "Strongly Agree." The items and reliability of each sub-variant are shown on [Table 4]. 
A Study on the Correlations of Self-Esteem Self-Efficacy, and Learning Motivations of Underachieving Elementary School Students

[Table 4] Sub-variables and Reliability of the Learning Motivation Scale

\begin{tabular}{cccc}
\hline Sub-variables & Number of Items & Items & Cronbach' $^{\prime}$ a \\
\hline Non-essential Motivations & 8 & $1,3,4,6,7,8,21,22$ & .87 \\
\hline Essential Motivations & 7 & $5,9,10,11,14,15,16$ & .84 \\
\hline Class Motivations & 4 & $12,13,18,19$ & .83 \\
\hline Continous Motivations & 6 & $2,17,20,23,24,25$ & .84 \\
\hline Total Learning Motivations & \multicolumn{2}{c}{25} & .92 \\
\hline
\end{tabular}

\subsection{Study Procedures and Data Processing}

This study was developed from September 2019 to February 2020 in stages of analyzing precedent studies, developing questionnaires, distributing questionnaires, and collecting them. The researchers visited elementary schools to conduct questionnaires for underachievement children, explain the purpose of the study and received consent from parents and children. The study followed research ethics to protect the participants so that the identities of underachievement children are not exposed.

General children were selected from the $50 \%$ to $60 \%$ percentile of academic levels, considering the grades and gender of underachievement children in each school.

Data from the study were statistically processed using SPSS 20.0, and the study conducted descriptive statistics, reliability analysis, t-tests, correlation analysis, and multiple regression analysis.

\section{Results}

\subsection{Differences in Self-esteem, Self-efficacy, and Learning Motivations of Underachievement Children and General Children}

As shown in [Table 5], there were significant differences by groups in total self-esteem $(t=2.78$, $\mathrm{p}<.01)$. In other words, underachievement children $(\mathrm{M}=3.38)$ showed lower self-esteem than general children $(\mathrm{M}=3.60)$. There were also significant differences in total self-efficacy as well $(t=4.59, \mathrm{p}<.001)$. That is, underachievement children $(\mathrm{M}=3.00)$ also showed lower total self-efficacy than general children $(M=3.28)$. There were significant differences in total learning motivations $(t=3.47, \mathrm{p}<.01)$, where underachievement children $(\mathrm{M}=3.05)$ showed lower learning motivations than general children $(\mathrm{M}=3.42)$. 

http://dx.doi.org/10.47116/apjcri.2020.08.08 [Table 5] Differences by Variable between Underachievement Children and General Children

\begin{tabular}{|c|c|c|c|c|c|c|}
\hline \multirow{2}{*}{ Variables } & \multicolumn{2}{|c|}{ General Children } & \multicolumn{2}{|c|}{ Underachievement Children } & \multirow{2}{*}{$\mathrm{t}$} & \multirow{2}{*}{$\mathrm{p}$} \\
\hline & $\mathrm{M}$ & SD & $\mathrm{M}$ & $\mathrm{SD}$ & & \\
\hline General Ego & 3.71 & .62 & 3.47 & .53 & $2.73^{* *}$ & .007 \\
\hline Social Ego & 3.45 & .55 & 3.26 & .61 & $2.16^{*}$ & .032 \\
\hline Family Ego & 3.63 & .75 & 3.47 & .58 & 1.63 & .103 \\
\hline Academic Ego & 3.50 & .72 & 3.21 & .65 & $2.76^{* *}$ & .006 \\
\hline Total Self-Esteem & 3.60 & .56 & 3.38 & .50 & $2.78^{* *}$ & .006 \\
\hline Confidence & 3.11 & .38 & 2.93 & .38 & $3.15^{* *}$ & .002 \\
\hline Self-control Efficacy & 3.31 & .53 & 2.99 & .44 & $4.39 * * *$ & .000 \\
\hline Preferences in Task Difficulties & 3.40 & .60 & 3.07 & .62 & $3.60 * * *$ & .000 \\
\hline Total Self-efficacy & 3.28 & .42 & 3.00 & .40 & $4.59^{* * *}$ & .000 \\
\hline Non-essential Motivations & 3.77 & .76 & 3.23 & .70 & $4.91^{* * *}$ & .000 \\
\hline Essential Motivations & 3.26 & .87 & 2.96 & .71 & $2.55^{*}$ & .011 \\
\hline Class Motivations & 3.35 & .90 & 3.05 & .72 & $2.46^{*}$ & .015 \\
\hline Continuous Motivations & 3.17 & .84 & 2.91 & .65 & $2.38^{*}$ & .018 \\
\hline Total Learning Motivations & 3.42 & .77 & 3.05 & .64 & $3.47^{* *}$ & .001 \\
\hline
\end{tabular}

*** p.001 ** $\mathrm{p}<.01 * \mathrm{p}<.05$

\subsection{Correlations between Self-Esteem, Self-Efficacy, and Learning Motivation of Underachievement Children and General Children}

[Table 6] Correlation between Self-esteem, Self-efficacy, and Learning Motivation of Underachievement Chlidren

\begin{tabular}{|c|c|c|c|c|c|c|c|c|c|c|c|c|c|}
\hline $\begin{array}{l}\text { Varia } \\
\text { bles }\end{array}$ & A & B & C & $\mathrm{D}$ & $\mathrm{E}$ & $\mathrm{F}$ & G & $\mathrm{H}$ & I & $\mathrm{J}$ & $\mathrm{K}$ & $\mathrm{L}$ & $\mathrm{M}$ \\
\hline B & $.92^{* * *}$ & & & & & & & & & & & & \\
\hline$C$ & $.82^{* * *}$ & $.72^{* * *}$ & & & & & & & & & & & \\
\hline $\mathrm{D}$ & $.75^{* * *}$ & $.56^{\star * *}$ & $.49^{* * *}$ & & & & & & & & & & \\
\hline$E$ & $.86^{* * *}$ & $.74^{\star * *}$ & $.61^{* * *}$ & $.59^{* * *}$ & & & & & & & & & \\
\hline $\mathrm{F}$ & $.66^{* * *}$ & $.62^{* * *}$ & $.63^{* * *}$ & $.47^{* * *}$ & $.56^{* * *}$ & & & & & & & & \\
\hline G & $.46^{\star * *}$ & $.46^{\star \star *}$ & $.45^{\star * *}$ & $.21^{*}$ & $.40^{* * *}$ & $.75^{\star \star *}$ & & & & & & & \\
\hline $\mathrm{H}$ & $.60^{* * *}$ & $.55^{* * *}$ & $.54^{* * *}$ & $.41^{* * *}$ & $.53^{* * *}$ & $.88^{* * *}$ & $.52^{* * *}$ & & & & & & \\
\hline I & $.58^{* * *}$ & $.53^{\star \star *}$ & $.57^{\star * *}$ & $.39^{* * *}$ & $.47^{\star * *}$ & $.86^{\star * *}$ & $.54^{\star * *}$ & $.60^{* * *}$ & & & & & \\
\hline $\mathrm{J}$ & $.43^{* * *}$ & $.41^{* * *}$ & $.29 * *$ & $.30^{* *}$ & $.44^{* * *}$ & $.48^{\star * *}$ & $.40^{* * *}$ & $.38^{* * *}$ & $.45^{\star * *}$ & & & & \\
\hline $\mathrm{K}$ & $.40^{* * *}$ & $.38^{* * *}$ & $.24^{*}$ & $.30^{* *}$ & $.42^{* * *}$ & $.42^{\star * *}$ & $.34^{* * *}$ & $.38^{* * *}$ & $.35^{* *}$ & $.92^{\star * *}$ & & & \\
\hline $\mathrm{L}$ & $.43^{* * *}$ & $.42^{* * *}$ & $28 * *$ & $.38^{* *}$ & $.43^{* * *}$ & $.47^{* * *}$ & $.36^{* * *}$ & $.34^{* *}$ & $.49^{* * *}$ & $.93^{* * *}$ & $.80^{* * *}$ & & \\
\hline $\mathrm{M}$ & $.35^{* *}$ & $.33^{* *}$ & $.28^{* *}$ & $.21^{*}$ & $.34^{* *}$ & $.48^{* * *}$ & $.47^{* * *}$ & $.34^{* *}$ & $.44^{* * *}$ & $.87^{* * *}$ & $.74^{* * *}$ & $.77^{* * *}$ & \\
\hline $\mathrm{N}$ & $.36^{* * *}$ & $.33^{* *}$ & $.27^{*}$ & $.26^{*}$ & $.38^{* * *}$ & $.41^{* * *}$ & $.35^{\star *}$ & $.32 * *$ & $.38^{* * *}$ & $.91^{\star * *}$ & $.78^{* * *}$ & $.83^{* * *}$ & $.76^{* * *}$ \\
\hline
\end{tabular}

As shown in [Table 6], there were significant correlations between learning motivations, self-esteem, and self-efficacy of underachievement children $(.29<\mathrm{r}<.48)$. 
A Study on the Correlations of Self-Esteem Self-Efficacy, and Learning Motivations of Underachieving Elementary School Students

[Table 7] Correlation between Self-esteem, Self-efficacy, and Learning Motivation of General Children

\begin{tabular}{|c|c|c|c|c|c|c|c|c|c|c|c|c|c|}
\hline $\begin{array}{l}\text { Varia } \\
\text { bles }\end{array}$ & A & B & C & $\mathrm{D}$ & $\mathrm{E}$ & $\mathrm{F}$ & G & $\mathrm{H}$ & I & $\mathrm{J}$ & K & $\mathrm{L}$ & $\mathrm{M}$ \\
\hline B & $.94^{\star * *}$ & & & & & & & & & & & & \\
\hline $\mathrm{C}$ & $.80^{* * *}$ & $.72^{* * *}$ & & & & & & & & & & & \\
\hline $\mathrm{D}$ & $.78^{* * *}$ & $.69^{* * *}$ & $.4^{* * *}$ & & & & & & & & & & \\
\hline$E$ & $.85^{\star * *}$ & $.71^{* * *}$ & $.70^{* * *}$ & $.55^{* * *}$ & & & & & & & & & \\
\hline $\mathrm{F}$ & $.68^{* * *}$ & $.66^{* * *}$ & $.59^{\star * *}$ & $.43^{* * *}$ & $.59^{* * *}$ & & & & & & & & \\
\hline G & $.23^{*}$ & $.19^{* * *}$ & $.26^{*}$ & $.12^{\star * *}$ & $.24^{*}$ & $.59^{\star * *}$ & & & & & & & \\
\hline $\mathrm{H}$ & $.65^{* * *}$ & $.62^{* * *}$ & $.56^{* * *}$ & $.46^{* * *}$ & $.57^{* * *}$ & $.92^{* * *}$ & $.38^{* * *}$ & & & & & & \\
\hline $\mathrm{I}$ & $.66^{* * *}$ & $.67^{* * *}$ & $.55^{* * *}$ & $.46^{* * *}$ & $.53^{* * *}$ & $.86^{* * *}$ & $.33^{* *}$ & $.68^{* * *}$ & & & & & \\
\hline $\mathrm{J}$ & $.48^{* * *}$ & $.45^{\star * *}$ & $.47^{* * *}$ & $.32^{* *}$ & $.42^{* * *}$ & $.60^{* * *}$ & $.31^{* *}$ & $.51^{* * *}$ & $.62^{* * *}$ & & & & \\
\hline $\mathrm{K}$ & $.42^{* * *}$ & $.39^{* * *}$ & $.44^{\star * *}$ & $.25^{*}$ & $.39^{* * *}$ & $.50^{\star * *}$ & $.23^{*}$ & $.42^{\star * *}$ & $.54^{\star \star *}$ & $.94^{\star * *}$ & & & \\
\hline $\mathrm{L}$ & $.51^{* * *}$ & $.48^{\star * *}$ & $.44^{\star * *}$ & $.36^{\star * *}$ & $.43^{\star * *}$ & $.64^{\star * *}$ & $.37^{* * *}$ & $.55^{\star * *}$ & $.61^{* \star *}$ & $.92^{\star * *}$ & $.81^{\star * *}$ & & \\
\hline $\mathrm{M}$ & $.38^{* * *}$ & $.33^{* *}$ & $.43^{* * *}$ & $.25^{*}$ & $.34^{* *}$ & $.48^{* * *}$ & $.31^{* *}$ & $.38^{* * *}$ & $.48^{* * *}$ & $.91^{* * *}$ & $.84^{\star * *}$ & $.80^{* * *}$ & \\
\hline $\mathrm{N}$ & $.45^{\star * *}$ & $.43^{* * *}$ & $.46^{* * *}$ & $.30^{* *}$ & $.38^{* * *}$ & $.59^{* * *}$ & $.25^{*}$ & $.50^{* * *}$ & $.63^{* * *}$ & $.93^{* * *}$ & $.83^{* * *}$ & $.81^{* * *}$ & $.82^{* * *}$ \\
\hline
\end{tabular}

As shown in [Table 7], there were significant correlations between learning motivations, self-esteem, and self-efficacy of general children $(.31<\mathrm{r}<.62)$.

\subsection{Predictors of Learning Motivations}

\subsubsection{Predictors of Learning Motivations for Underachievement Children}

A regression analysis was performed to identify the factors that affect the learning motivations of underachievement children.

[Table 8] Predictors of Learning Motivations for Underachievement Children

\begin{tabular}{cccccccccc}
\hline Variables & $\mathrm{B}$ & $\mathrm{SE}$ & $\mathrm{\beta}$ & $\mathrm{t}$ & $\mathrm{p}$ & $\mathrm{R}^{2}$ & $\triangle \mathrm{R}^{2}$ & $\mathrm{~F}$ & $\mathrm{VIF}$ \\
\hline Constant & .49 & .54 & - & .90 & .368 & & & & - \\
General Ego & .14 & .19 & .12 & .72 & .469 & & & & 3.18 \\
Social Ego & -.23 & .15 & -.22 & -1.53 & .129 & & & & 2.45 \\
Family Ego & .04 & .13 & .04 & .34 & .731 & & & 5.27 & 1.71 \\
Academic Ego & .24 & .14 & .24 & 1.67 & .098 & .313 & .254 & $(.000)$ & 2.56 \\
Confidence & .30 & .19 & .18 & 1.54 & .125 & & & & 1.65 \\
Self-control Efficacy & .04 & .18 & .03 & .25 & .801 & & & & 1.96 \\
Preferences in Task & .27 & .13 & .26 & $2.03^{*}$ & .046 & & & & 1.99 \\
Difficulties & & & & & & & & & \\
\hline
\end{tabular}

As shown in [Table 8], the sub-variables of self-esteem (general ego, social ego, family ego, academic ego) and the sub-variables of self-efficacy (confidence, self-control efficacy, preferences 
in task difficulties) were set as independent variables, and learning motivations were entered as dependent variables to conduct a multiple regression analysis. After analyzing the regression model, it was shown that the factor that affects the learning motivations of underachievement children was preferences in task difficulties $(\beta=.26, p<.05)$, with an explanatory power of $25.4 \%$ for learning motivations $(\mathrm{F}=5.27, \mathrm{p}<.001)$.

\subsubsection{Predictors of Learning Motivations for General Children}

A regression analysis was performed to identify the factors that affect the learning motivations of general children.

[Table 9] Predictors of Learning Motivations for General Children

\begin{tabular}{cccccccccc}
\hline Variables & $\mathrm{B}$ & $\mathrm{SE}$ & $\mathrm{\beta}$ & $\mathrm{t}$ & $\mathrm{p}$ & $\mathrm{R}^{2}$ & $\triangle \mathrm{R}^{2}$ & $\mathrm{~F}$ & $\mathrm{VIF}$ \\
\hline Constant & -.19 & .62 & - & -.30 & .760 & & & & - \\
General Ego & -.19 & .21 & -.15 & -.87 & .383 & & & & 4.37 \\
Social Ego & .28 & .19 & .20 & 1.49 & .139 & & & & 2.72 \\
Family Ego & .04 & .12 & .04 & .39 & .698 & & & 8.78 & 2.07 \\
Academic Ego & .04 & .14 & .04 & .32 & .747 & .428 & .380 & $(.000)$ & 2.56 \\
Confidence & .16 & .18 & .07 & .85 & .397 & & & & 2.23 \\
Self-control Efficacy & .12 & .18 & .08 & .64 & .518 & & & & 2.31 \\
Preferences in Task & .61 & .16 & .48 & $3.72^{* * *}$ & .000 & & & & 2.39 \\
Difficulties & & & & & & & &
\end{tabular}

As shown in [Table 9], the self-esteem (general ego, social ego, family ego, academic ego) and the self-efficacy (confidence, self-control efficacy, preferences in task difficulties) were set as independent variables. Learning motivation was introduced as a dependent variable, and regression analysis was conducted. After analyzing the regression model, it was shown that the factor that affects the learning motivations of general children was preferences in task difficulties $(\beta=.48, p<.001)$, with an explanatory power of $38.0 \%$ for learning motivations $(\mathrm{F}=8.78, \mathrm{p}<.001)$.

\section{Discussions and Conclusions}

The conclusions according to the findings of the study are as follows.

First, underachievement children showed lower self-esteem, self-efficacy, and learning motivations than general children. In other words, underachievement children consider themselves unacknowledged by others as they have negative self-esteem, lack in confidence, belittle themselves and have strong sense of inferiority[13][14]. As such, continuous performance of 
A Study on the Correlations of Self-Esteem Self-Efficacy, and Learning Motivations of Underachieving Elementary School Students

tasks and results of task performance to determinedly try to achieve goals are related to the self-efficacy of individuals[15][16]. They also have poor academic achievement due to low interest in learning and lack of motivations[11].

Second, it was found that the predictor for learning motivations for underachievement children was preferences in task difficulties. Underachievement children tend to easily give up when they face difficulties, do not try to analyze the cause and effects, have difficulties in setting up goals, and do not feel interested in challenging activities[17].

Suggestions for this study are as follows. The research tool of this study needs to be reduced because elementary school students have access to it and there are many questions. In addition, for in-depth understanding of children with poor learning, it is necessary to conduct qualitative research such as interview methods.

Therefore, this study suggests that it is necessary to provide a variety of programs for improving self-esteem and learning motivation for underachievement children. In particular, it is necessary to approach education for underachievement children in elementary school proactively.

\section{Acknowledgement}

This study was supported (in part) by research funds from Nambu University, 2020.

\section{References}

[1] S. Kim, K. O. Kim, S. D. Kim, S. D. Lee, H. S. Lim, S. M. Han, Underachievement children's understanding and education, Korea Seoul: Hakjisa, (2001)

[2] H. J. Yi, M. J Kim, D. S. Lee, S. H. Sohn, Seeking for the better instruction and support for low achievers in schools: A Framework for educational policy-making for low achievers, Korea: KICE, (2009)

[3] J. Hyun, Y. J. Park, J. B. Lee, I. Y. Park, Elementary school basic and basic learning Underachievement student discrimination tool: Elementary school 5th and 6th grade, Korea Seoul: Korean Educational Development Institute, (2000)

[4] S. I. Park, Education for underachievement children, Korea Seoul: Korean Educational Development Institute, (1986)

[5] J. H. Kim, Suggests alternatives to Underachievement and learning disabilities, Baeum ChanChan research project, Korea: Good Teacher Movement, (2013)

[6] M. H. Hwang, Y. B. Kim, E. H. Ham, S. C. Oh, Exploring the types of academic underachievement, Secondary Education Research, (2012), Vol.60, No.1, pp.191-217. 
[7] S. J. Kang, The effects of self disclosure training on self-esteem sociality of underachievers, Daegu University, Master's Thesis, (2006)

[8] C. U. Gang, Understanding and education of special children, Korea Seoul: Bakhaksa, (2004)

[9] S. Coopersmith, The antecedents of self-esteem, USA CA: Consulting Psychologists Press, (1970)

[10] M. A. Lim, The effects of speech anxiety of elementary student's on self-esteem and school adaptation, Inje University, Master's Thesis, (2007)

[11] A. Y. Kim, Academic self-efficacy, Korea Seoul: Hakjisa, (2008)

[12] Y. R. Kim, An Analysis on the validation of school learning motivation scale(A) \& school-related coping scale(B) and relations between (A) \& (B), Hongik Journal of Educational Research, (2000), Vol.17, pp3-39.

[13] J. H. Hwang, Comparative study for self-Esteem of high-achievers' and low-achievers', Deagu University, Master's Thesis, (2003)

[14] J. H. Kim, H. J. Choi, H. K. Kim, The effect of obesity on adolescent development: relationship between self-Efficacy, parent-child relationship, peerlessness, and self-esteem, International Journal on Consulting Psychology for Patients, (2018), Vol.2, No.2, pp.69-76.

[15] Y. M. Kim, The effects of a successful experiences-based program on the self efficacy and academic achievement of elementary school student, Busan National University of Education, Master's Thesis, (2008)

[16] S. Y. Hong, Relation among stress ego-resilience, self-efficacy, clinical performance in graduate medical student, Journal of Korea Academia-industrial Cooperation Society, (2011), Vol.12, No.12, pp.5797-5804.

[17] A. Bandura, Social foundations of thought and action: A social cognitive theory, USA NJ: Prentice Hall, (1986) 